\title{
Perangkat Lunak Mobile Trivia Game Untuk Membantu Meningkatkan Hafalan Dan Wawasan Anak-Anak Terhadap Surah Pendek Al-Qur'an
}

\author{
Listiananda Apriliawan ${ }^{1}$, Afriyudi², Siti Sauda³ \\ 1,3Informatics Departement, Universitas Bina Darma, Palembang, Indonesia \\ 2 Information System Departement, Universitas Bina Darma, Palembang, Indonesia \\ Email:141420090@student.binadarma.ac.id¹, babeyudi@binadarma.ac.id², \\ siti_sauda@binadarma.ac.id³
}

\begin{abstract}
The development of mobile trivia game software is motivated by the tendency of children over the age of 7 who prefer digital devices and are better able to utilize the information presented by games. The mobile trivia game software is expected to be a solution that can meet the needs of children aged over 7 years starting from the aspect of education which is very important to be a shared concern for all elements in the society. The development of the software system can be realized by using the Extreme Programming method which modeling can use a CRC card. The work is done in a very short time. The results of the implementation of the development of mobile trivia game software can provide benefits to children aged over 7 years, especially to help improve their memorization and insight into the Qur'an's Juz Amma. As has become the hope for the author, namely creating educational software for children over 7 years.
\end{abstract}

Keywords: Software, Mobile, Trivia Game, Al-Qur'an, Extreme Programming

\section{PENDAHULUAN}

Al-Qur'an adalah mukjizat sepanjang zaman, yang dijadikan Allah sebagai jawaban bagi jin dan manusia yang meragukan kebenarannya serta bantahan bagi semua golongan yang menyimpang. Sampai kapan pun Al-Qur'an tidak akan hilang, karena sering diulang dan tidak akan pudar meskipun zaman terus berganti. Sebagaimana dalam Kitab At-Tibyaan fii Aadaabi Hamalatil Quran, Imam Nawawi menerangkan bahwa Allah telah menjadikannya mudah sebagai pelajaran, sehingga anak-anak yang belum baligh pun bisa hafal Al-Qur'an. Allah telah menjamin keasliannya, sehingga akan senantiasa terjaga dari perubahan dan pembaharuan. la akan senantiasa terpelihara selama malam dan siang datang dan pergi secara bergantian. Allah telah memilih orang-orang yang memiliki kecerdasan dan ketekunan untuk dimudahkan memberi perhatian 
kepadanya, sehingga berhasil menghimpun berbagai bidang ilmu mengenainya yang melegakan dada orang-orang beriman.

Permasalahan yang sering dihadapi oleh anak-anak pada usia di atas 7 tahun berkaitan dengan kegiatannya dalam menghafalkan surah pendek maupun mempelajarinya adalah minimnya kedisiplinan yang diterapkan orang tua ketika berada di luar jam belajar formal. Hal ini didukung dengan hasil riset oleh Kementerian Komunikasi dan Informatika dan United International Children's Fund (UNICEF) tentang perilaku anak dan remaja dalam menggunakan internet yang dipublikasi dalam Siaran Pers No.17/PH/KOMINFO/2/2014.

Dijelaskan bahwa anak-anak pada usia di atas 7 tahun cenderung menggunakan smartpnhone untuk mengunduh perangkat lunak game dan memainkannya. Minimnya perhatian dari kebanyakan orang tua yang bahkan tidak memberikan batasan menyebabkan anak-anak sering bermain game dalam waktu yang sangat lama. Hal ini akan berpengaruh terhadap kegiatan belajar dan menghafal surah pendek Al-Qur'an bagi anak tersebut. Oleh karena itu penulis berupaya menciptakan sebuah perangkat lunak mobile game bergenre trivia yang bersifat edukatif guna membantu kegiatan menghafal dan mempelajari surah pendek AlQur'an bagi anak-anak.

Sebagaimana telah dilansir oleh technoid (2015), bahwa permainan trivia game mengandalkan pengetahuan umum dari pemainnya. Pemain yang mampu menjawab pertanyaan paling banyaklah yang kemudian menjadi pemenangnya. Trivia biasanya diawali dengan pertanyaan "apakah anda tahu?" atau "tahukah anda?". Artinya mobile game bergenre trivia adalah permainan menjawab pertanyaan berbasis mobile yang dalam hal ini pertanyaannya adalah tentang surah pendek Al-Qur'an dengan tujuan untuk meningkatkan hafalan dan wawasan anak-anak terhadap surah pendek Al-Qur'an. Berdasarkan uraian tersebut, penulis berupaya untuk membuat penelitian dengan judul "Perangkat Lunak Mobile Trivia Game Untuk Membantu Meningkatkan Hafalan dan Wawasan Anak-anak Terhadap Surah Pendek Al-Qur'an" dengan harapan perangkat lunak mobile ini akan bermanfaat bagi masyarakat khususnya anakanak yang senang bermain game namun tetap berkeinginan mengningkatkan hafalan surah pendek dan wawasan Al-Qur'an.

\section{METHODS}

\subsection{Metode Pengumpulan Data}

Di dalam penelitian ini, pasti menggunakan data. Untuk dapat mengumpulkan data yang diperlukan dalam upaya membangun perangkat lunak mobile trivia game, menggunakan beberapa metode. Adapun diantaranya adalah: 
1) Kepustakaan, menurut Nazir (1998), kepustakaan merupakan langkah yang penting dimana setelah seorang peneliti menetapkan topik penelitian, langkah selanjutnya adalah melakukan kajian yang berkaitan dengan teori yang berkaitan dengan topik penelitian. Dalam pencarian teori, peneliti akan mengumpulkan informasi sebanyak-banyaknya dari kepustakaan yang berhubungan.

2) Dokumentasi, menurut Arikunto (2006), dokumentasi adalah mencari dan mengumpulkan data mengenai hal-hal yang berupa catatan, transkrip, buku, surat kabar, majalah, notulen, rapot, agenda dan sebagainya.

\subsection{Metode Penelitian}

Dalam kegiatan rancang bangun perangkat lunak mobile trivia game, penulis menggunakan metode Penelitian Tindakan atau Action Research. Menurut Martinson \& Kock (2004), menyebutkan penelitian tindakan, sebagai sebuah metode penelitian, didirikan atas asumsi bahwa teori dan praktik dapat secara tertutup diintegrasikan dengan pembelajaran dari hasil intervensi yang direncanakan setelah diagnosis yang rinci terhadap konteks masalahnya

\subsection{Metode Pengembangan Sistem}

Metode yang digunakan dalam pengembangan aplikasi ini adalah metode Extreme Programming (XP). Menurut Pressman (2010), XP merupakan salah satu metode pengembangan software yang termasuk dalam Agile Software Development. XP menggunakan pendekatan object-oriented. Tahapan yang digunakan dalam metode XP terdiri dari empat bagian pokok yaitu:

1) Planning Tahap planning dilakukan dengan membuat sebuah dokumentasi yang menjelaskan output, fitur dan fungsional dari perangkat lunak yang dibuat.

2) Design Design pada XP dilakukan dengan mengikuti prinsip Keep It Simple (KIS). Desain yang lebih sederhana selalu lebih disukai dibandingkan dengan desain yang complex. Untuk desain yang sulit, XP akan menggunakan Spike Solution dimana pembuatan desain dibuat langsung ke tujuan. XP juga mendukung adanya refactoring dimana software system diubah sedemikian rupa dengan cara mengubah struktur kode dan menyederhanakan kode.

3) Coding Tahap XP ini diawali dengan membangun serangkaian tes (unit test), setelah itu pengembang harus berfokus kepada implementasi untuk melewati tes. Dalam XP juga diperkenalkan istilah Pair Programming dimana proses penulisan program dilakukan secara 
berpasangan. Dua orang programmer saling bekerja sama di satu komputer untuk menulis program. Dengan melakukan ini akan didapat real-time problem solving dan real-time quality assurance.

4) Testing, acceptance test atau biasa disebut customer test. Pengujian ini dilakukan oleh customer yang berfokus kepada fitur dan fungsi dari sistem secara keseluruhan.

\section{HASIL DAN PEMBAHASAN}

Hasil yang dicapai dalam penelitian ini sesuai dengan metode pengembangan extame programming berupa perangkat lunak mobile trivia game yang telah didokumentasikan (interface) tampilannya

\subsection{Hasil Interface}

Dokumentasi prototipe menggambarkan wujud tampilan user interface dari perangkat lunak yang akan dibuat. Setelah melewati tahap iterasi, pengembang kembali melakukan coding, untuk menyempurkan perangkat lunak agar sesuai dengan keinginan pengguna. Berikut adalah dokumentasi perangkat lunak sudah sesuai dengan keinginan pengguna.

\section{1) Halaman Utama}

Halaman utama utama adalah halaman utama pada game yang menampilkan menu-menu game yang meliputi menu-menu pilihan permainan beserta button music, dan button SFX. Adapun rancangan halaman utama adalah sebagai berikut:

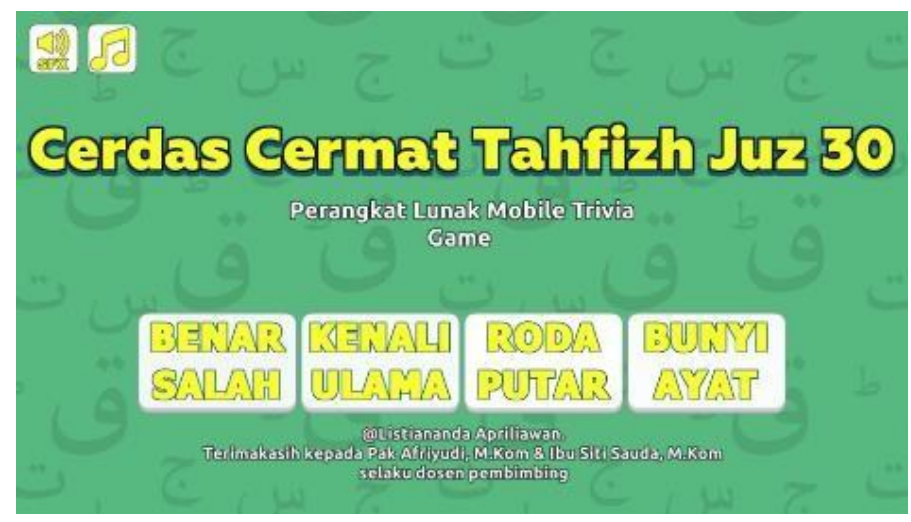

Gambar 1. Tampilan Halaman Utama

Pada gambar tampilan halaman utama pengembang berusaha memenuhi keinginan dari pengguna melalui feedback yang pernah mereka sampaikan selama proses iterasi. Dalam hal ini pengembang melengkapi halaman utama 
dengan fitur button music dan SFX. Maka pengguna dapat mengaktifkan atau menonaktifkan bunyi music dan SFX.

\section{2) Halaman Arena Permainan Benar Salah}

Halaman arena permainan Benar Salah adalah arena permainan dalam perangkat lunak mobile trivia game yang menantang pengguna sebagai player untuk menentukan soal-soal trivia yang dipaparkan tersebut betul atau salah. Apabila pengguna memilih jawaban yang salah, maka sistem akan menampilkan highlight yang menunjukan jawaban betul kepada pengguna. Dengan demikian diharapkan melalui pengalaman bermain permainan Benar Salah dapat meningkatkan wawasan pengguna terhadap Al-Qur'an. Berikut adalah gambar arena permainan Benar Salah:

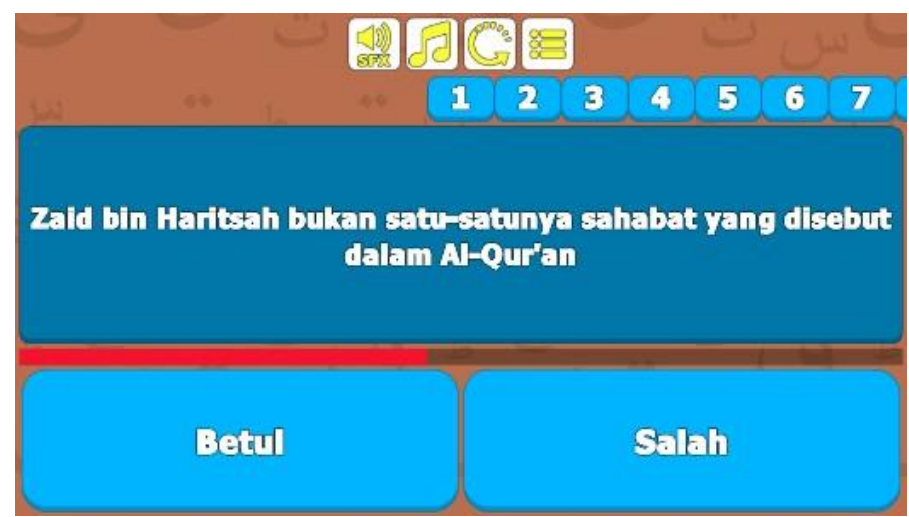

Gambar 2. Tampilan Arena Permainan Benar Salah

\section{3) Halaman Arena Permainan Kenali Ulama}

Pada halaman arena permainan Kenali Ulama, pengguna akan dihadapkan dengan tantangan harus mengenali foto atau gambar para ulama yang ditampilkan oleh sistem. Apabila pengguna sebagai pemain salah menentukan jawaban, maka sistem akan memberikan deskripsi singkat tentang foto salah satu ulama yang ditampilkan. Permainan ini ditujukan kepada pengguna khususnya anakanak pada usia diatas 7 tahun, supaya lebih mengenali dan menyenangi tokoh-tokoh ulama. Sebagaimana yang diharapkan oleh para orang tua agar anaknya memiliki sosok idola yang bagus untuk diteladani. Kemudian memalui hal ini, anak-anak merasa terinspirasi untuk mempunyai hingga mencapai cita-cita yang baik. Berikut adalah gambar arena permainan Kenali Ulama: 


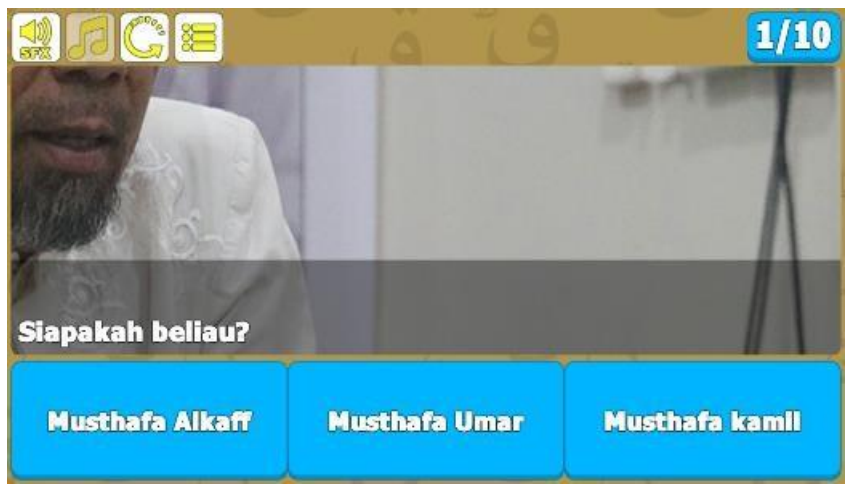

Gambar 3. Tampilan Arena Permainan Kenali Ulama

4) Halaman Arena Permainan Roda Putar

Pada arena permainan Roda Putar ini, bidang pertanyaan yang akan diberikan ada 3 saja. Namun sistem pemilihannya akan diberikan secara acak melalui roda yang berputar (roullete). Diharapkan hal ini akan meningkatkan keasyikan bagi pengguna. Berikut adalah gambar tampilan awal arena permainan Roda Putar:

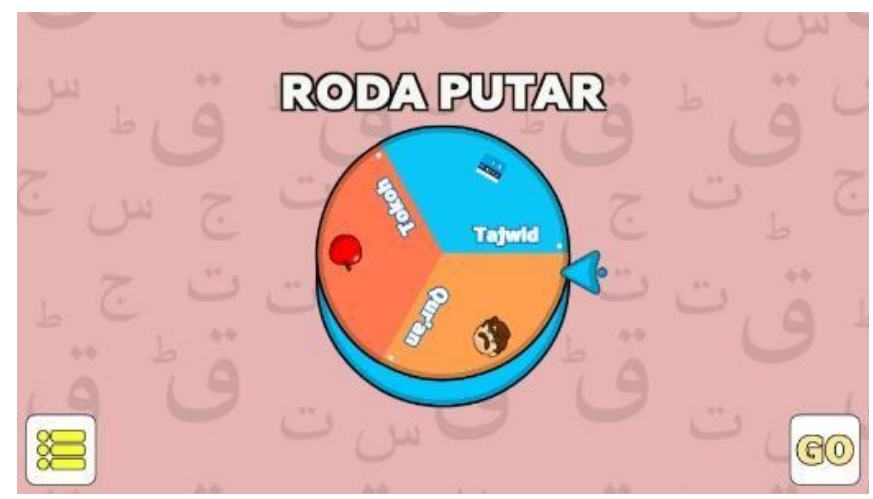

Gambar 4. Tampilan Awal Arena Permainan Roda Putar.

Adapun opsi jawaban yang ditampilkan oleh sistem ada 4 opsi. Pada setiap sesi pertanyaan penguna dibatasi dengan perhitungan mundur sebuah timer. Maka penguna harus mampu memilih jawaban yang benar dalam waktu yang dibatasi 8 detik saja. Ketika jawaban yang dipilih pengguna adalah jawaban yang tidak tepat, maka pengguna akan ditunjukan jawaban yang benar melalui highlight, berupa kedipan warna pada opsi jawaban yang benar. Diharapkan dengan adanya arena permainan Roda Putar, pengguna perangkat lunak yang dalam hal ini adalah anak-anak dapat mempelajari hal -hal yang belum mereka diketahui. 
Sehingga melalui pengalaman bermain tersebut, dapat meningkatkan wawasan mereka terhadap Al-Qur'an. Berikut adalah gambar arena permainan Roda Putar:

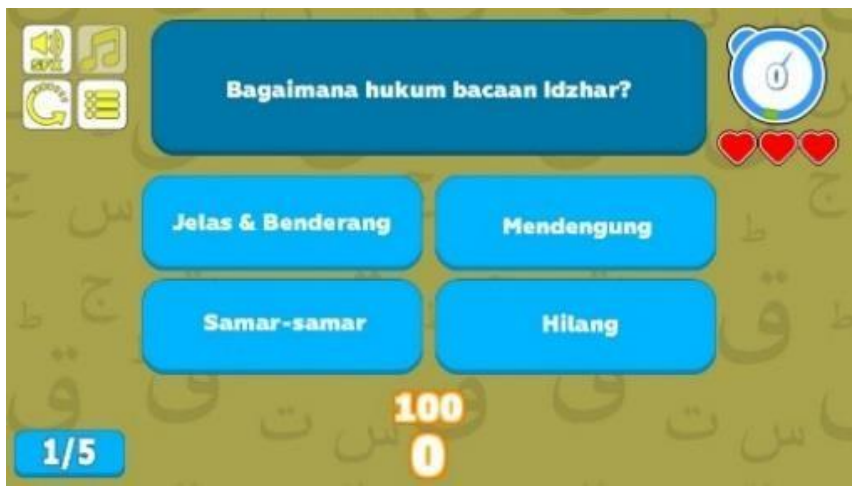

Gambar 5. Tampilan Arena Permainan Roda Putar

5) Halaman Arena Permainan Bunyi Ayat

Pada arena permainan Bunyi Ayat, pengguna akan diperdengarkan bunyi-bunyi ayat dari salah satu surah pendek Al-Qur'an. Setelah itu pengguna harus menentukan nama surah dari ayat tersebut dalam batasan waku hanya 13 detik saja. Tujuan dari arena permainan ini adalah untuk melatih kemampuan pengguna khususnya anak-anak pada usia diatas 7 tahun untuk mengenali, mengingat, dan menghafalkan kembali bunyi-bunyi ayat yang sudah pernah mereka hafalkan sebelumnya. Maka dari itu pengguna harus mampu mengenali bunyi ayat, nomor ayat, nama surah. Pada dasarnya dengan memainkan permainan Bunyi Ayat berkali-kali dapat membantu pengguna untuk mampu mengenali ayat-ayat yang diperdengarkan oleh sistem dan menghafalkannya. Berikut adalah gambar arena permainan Bunyi Ayat:

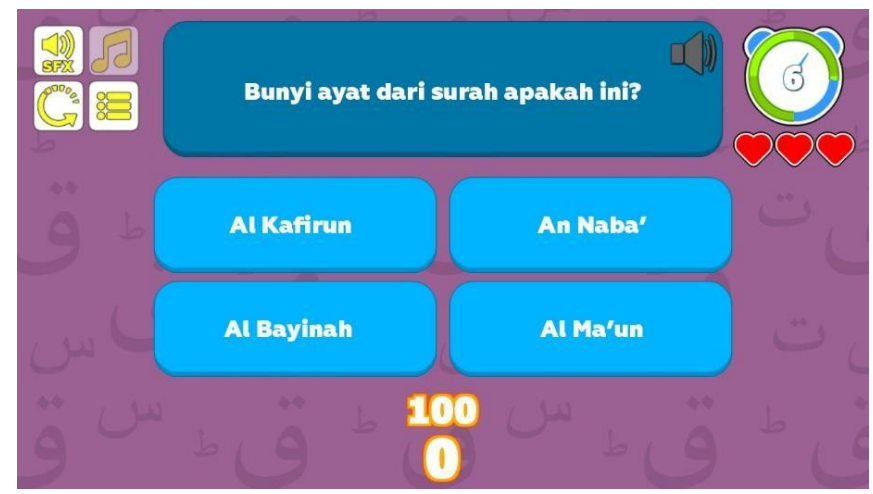

Gambar 6. Tampilan Arena Permainan Bunyi Ayat 


\section{6) Halaman Hasil Permainan}

Pada arena permainan yang telah dituntaskan, sistem akan menampilkan hasil akhir permainan kepada pengguna baik itu menang ataupun kalah. Sebagai upaya untuk mewujudkan tren positif di kalangan pengguna perangkat lunak khususnya anak-anak, maka perlu dibuat tampilan hasil permainan yang baik dan sesuai dengan etika bermain. Ketika pengguna berhasil meraih kemenangan sistem akan menampilkan nilai score nya beserta tulisan "ALHAMDULILLAH", namun apabila pengguna mengalami kekalahanaka akan ditampilkan tulisan "AYO COBA LAGI" oleh sistem. Dengan demikian pengguna perangkat lunak khususnya anak-anak pada usia diatas 7 tahun tersebut tetap termotivasi untuk tidak menyerah pada kegagalan. Berikut adalah hasil tampilan apabila pengguna meraih kemenangan pada permainan:

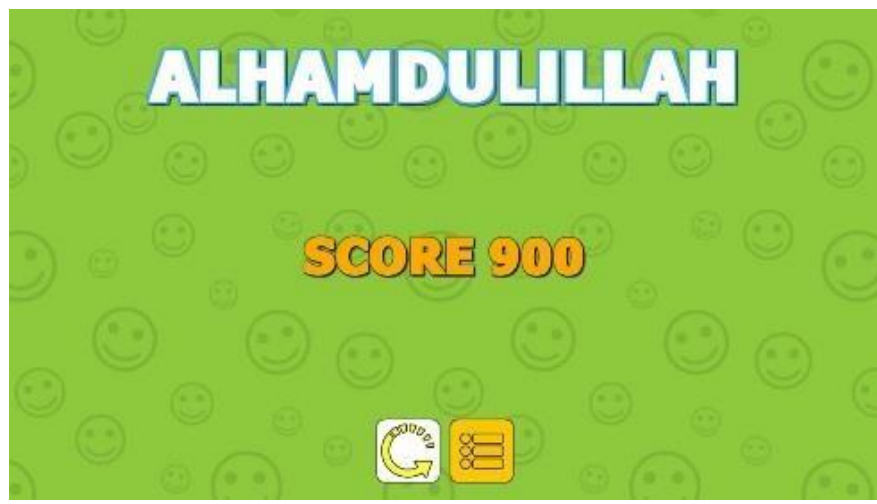

Gambar 7. Tampilan Hasil Kemenangan

Berikut adalah hasil tampilan apabila pengguna meraih kekalahan pada permainan:

\section{AYO COBA LAGI}

\section{SCOR 200}

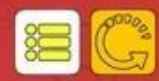

Gambar 8. Tampilan Hasil Kekalahan 


\section{KESIMPULAN}

Simpulan yang dapat diambil dalam penulisan ini antara lain adalah sebagai berikut:

1) Perangkat lunak mobile trivia game ditujukan kepada anak-anak pada usia di atas 7 tahun.

2) Perangkat lunak mobile trivia game ini memiliki 4 buah jenis permainan, yaitu benar salah, kenali ulama, roda putar, dan bunyi ayat. Setiap jenis permainan pada perangkat lunak tersebut memuat konsep arena permainan yang berbeda-beda.

3) Pada beberapa permainan telah memiliki fitur Timer yang digunakan untuk membatasi waktu berpikir pengguna dalam menjawab soal-soal trivia yang ditanyakan.

4) Dari hasil pengujian yang telah dilakukan dengan melibatkan pengguna, didapatkan hasil perangkat lunak mobile trivia game yang sesuai dengan keinginan pengguna.

\section{DAFTAR PUSTAKA}

Chowanda, A. Dkk. 2014. Tap For Battle: Perancangan Casual Game Pada Smartphone Android. ComTech Vol V No.2, Desember 2014.

Garagenta, Marko. 2011. Learning Android-First Edition. United State of America. O'reillyMedia.Inc.

Leyton-Brown, K. dan Shoham. 2008. Essentials of Games Theory. United States of America: Morgan \& Claypool.

Madya, S. 2006. Teori dan Praktik Penelitian Tindakan Action Research, Bandung: Alfabeta.

Meier, Reto. 2009. Professional Android'T 4 Application Development. United States of America: Wiley Publishing, Inc.

Moeliono, M. Dkk. 1988. Kamus Besar Bahasa Indonesia. Jakarta: Balai Pustaka. Schell, J. 2008. The Art of Game Design A Book Of Lenses. United States of America: Morgan Kaufmann Publishers.

Davison, R. M., Martinson, M. G.. \& Kock, N. 2004. "Principles of Canoncial Action Research". Information System Journal 14, 65-86.

Yahya, A Z. 2015. Adab Penghafal Al-Qur'an (At-Tibyan fi Adabi Hamalatil). Bandung: Al-Qawam 
Rosa, Salahudin., 2015. Rekayasa Perangkat Lunak Terstruktur dan Berorientasi

Objek. Bandung: Informatika

Suryantara, I.G.N. 2017. Merancang Aplikasi dengan Metodologi Extreme

Programming. Jakarta: Gramedia

Arikunto, S. 2014. Evaluasi Program Pendidikan. Jakarta: Bumi Aksara.

Roedaven, R. 2016. Unity Tutorial Game Engine. Bandung: Informatika

Hamzah. 2011. Teknologi Komunikasi Dan Informasi Pembelajaran. Jakarta: Bumi Aksara.

Wadoyo. S. M. 2013. Pembelajaran Kontruktivisme Teori dan Aplikasi Pembelajaran dalam Pembentukan Karakter. Bandung: Alfabeta.

Departemen Agama RI. 2005. Al-qur'an Dan Terjemahnya. Bandung: Diponegoro.

Tirtarahardja. U. 2010. Pengantar Pendidikan. Jakarta: Rineka Cipta. 